OPEN ACCESS

Edited by:

Carmen Scheibenbogen, Charité - Universitätsmedizin

Berlin, Germany

Reviewed by:

Getnet Ali,

The Ohio State University,

United States

Mustafa Al-Zoughool,

Health Science Center, Kuwait

*Correspondence:

Peter C. Rowe

prowe@jhmi.edu

Specialty section:

This article was submitted to Infectious Diseases - Surveillance,

Prevention and Treatment,

a section of the journal

Frontiers in Medicine

Received: 17 February 2021

Accepted: 29 March 2021

Published: 29 April 2021

Citation:

Petracek LS, Suskauer SJ, Vickers RF Patel NR, Violand RL, Swope RL and

Rowe PC (2021) Adolescent and Young Adult ME/CFS After Confirmed or Probable COVID-19.

Front. Med. 8:668944.

doi: 10.3389/fmed.2021.668944

\section{Adolescent and Young Adult ME/CFS After Confirmed or Probable COVID-19}

\author{
Lindsay S. Petracek ${ }^{1}$, Stacy J. Suskauer ${ }^{1,2}$, Rebecca F. Vickers ${ }^{3}$, Neel R. Patel ${ }^{4}$, \\ Richard L. Violand ${ }^{5}$, Renee L. Swope ${ }^{1}$ and Peter C. Rowe ${ }^{\text {1* }}$ \\ ${ }^{1}$ Departments of Pediatrics, The Johns Hopkins University School of Medicine and the Kennedy Krieger Institute, Baltimore, \\ MD, United States, ${ }^{2}$ Departments of Physical Medicine and Rehabilitation, The Johns Hopkins University School of Medicine \\ and the Kennedy Krieger Institute, Baltimore, MD, United States, ${ }^{3}$ Arundel Pediatrics, Arnold, MD, United States, ${ }^{4}$ Central \\ Florida Heart Care, Maitland, FL, United States, ${ }^{5}$ Rick Violand, PT, LLC, Ellicott City, MD, United States
}

Introduction: Fatigue is a common acute symptom following SARS-CoV-2 infection (COVID-19). The presence of persistent fatigue and impaired daily physical and cognitive function has led to speculation that like SARS-CoV-1 infection, COVID-19 will be followed by myalgic encephalomyelitis/chronic fatigue syndrome (ME/CFS).

Methods and Results: We describe three adolescent and young adult patients who had confirmed or probable COVID-19 infections early on during the pandemic and were referred for evaluation to the Chronic Fatigue Clinic at the Johns Hopkins Children's Center. All patients reported orthostatic intolerance symptoms within the first 2 weeks of illness, and 10-min passive standing tests were consistent with postural tachycardia syndrome. After 6 months of illness, all three patients met criteria for ME/CFS. Clinical features of interest included strong histories of allergies in all three patients, two of whom had elevations in plasma histamine. Each demonstrated limitations in symptom-free range of motion of the limbs and spine and two presented with pathological Hoffman reflexes. These comorbid features have been reported in adolescents and young adults with ME/CFS.

Conclusion: ME/CFS can be triggered by COVID-19 in adolescents and young adults. Further work is needed to determine the pathogenesis of ME/CFS after COVID-19 and optimal methods of treating these patients. Our preliminary study calls attention to several comorbid features that deserve further attention as potential targets for intervention. These include neuromuscular limitations that could be treated with manual forms of therapy, orthostatic intolerance and POTS for which there are multiple medications and non-pharmacologic therapies, treatable allergic and mast cell phenomena, and neurologic abnormalities that may require specific treatment. Larger studies will need to ascertain the prevalence of these abnormalities.

Keywords: chronic fatigue syndrome, myalgic encephalomyelitis, dysautonomia, postural tachycardia syndrome, Hoffman sign, COVID-19, mast cell activation, neurodynamics 


\section{INTRODUCTION}

The occurrence of chronic fatigue and other symptoms following infection with SARS-CoV-2 (COVID-19) has fueled speculation that the COVID-19 pandemic will trigger a wave of new cases of myalgic encephalomyelitis/chronic fatigue syndrome (ME/CFS) $(1,2)$. As currently defined, the diagnosis of ME/CFS requires a duration of at least 6 months together with a substantial impairment in previously tolerated activities usually accompanied by profound fatigue, post exertional malaise (PEM), unrefreshing sleep, and either cognitive impairment or orthostatic intolerance (3). The diagnosis of ME/CFS requires a careful history and examination, and it should be brought into question if these symptoms are not present for the majority of the time and with at least a moderate severity.

Orthostatic intolerance refers to a group of clinical conditions in which symptoms of fatigue, lightheadedness, difficulty concentrating, and others are aggravated by quiet upright posture and are ameliorated by recumbency (4). Among those with ME/CFS, orthostatic intolerance is found in $90 \%$ of adults and over $95 \%$ of adolescents $(3,5-7)$. There has been some uncertainty about whether orthostatic intolerance is an early and primary contributor to ME/CFS symptoms, or if it develops as a secondary phenomenon due to reduced activity or some other aspect of disease pathophysiology. This question can be difficult to resolve because the onset of ME/CFS can be insidious. Even when there has been an obvious post-infectious onset, the diagnosis of ME/CFS is made long after the acute illness, making the timing of symptom recall subject to bias.

We recently evaluated three adolescents and young adults in whom COVID-19 illness had been confirmed with direct testing or was highly suspected based on the timing of the onset of symptoms in association with peak local and regional pandemic cases, close exposure to confirmed cases, along with characteristic clinical features such as anosmia. In all three, ME/CFS symptoms were prominent from the outset, as were symptoms and signs of orthostatic intolerance, consistent with an early contribution of circulatory disturbances to the pathogenesis of symptoms, before the onset of physiological changes due to inactivity. The preliminary findings of this case series have the potential to inform the investigation and treatment of what has been termed "long COVID" (8) or post-COVID-19 ME/CFS.

\section{PARTICIPANTS AND METHODS}

For this case series, eligible participants were individuals who had a confirmed or probable exposure to COVID-19 during the pandemic period and who had been referred to the Chronic Fatigue Clinic at the Johns Hopkins Children's Center after April of 2020. All individuals underwent a careful history and physical examination by a clinician with experience in the evaluation of ME/CFS. As part of routine procedure in the Chronic Fatigue Clinic, all individuals completed the unidimensional Wellness score which asks, "On a scale of 0-100 (with 0 being dying and 100 being the best a person can feel), how would you rate yourself on average over the last month?" This scale correlates well with longer questionnaires that measure health related quality of life (9).

Based on prior publications from our group and others about risk-factors for ME/CFS, the physical examination included an evaluation of joint hypermobility, screening maneuvers to identify limitations in symptom-free range of motion of the limbs and spine, a careful neurologic examination for evidence of myelopathy, orthostatic testing, and ascertainment of symptoms consistent with allergic inflammation and mast cell activation syndrome (10-13).

All patients had a general physical examination that included the nine-point Beighton score, a commonly used and reliable measure of joint hypermobility. Joint hypermobility was considered present if the Beighton score was four or higher. As part of the neurologic examination, all patients had an ascertainment of deep tendon reflexes and a Hoffman sign. The Hoffman sign was performed with the patient seated and with the head and neck in a neutral position. With the patient's distal interphalangeal joint of the middle finger supported by the examiner's index finger, the examiner's thumb made an abrupt downward flicking of the patient's distal phalanx. The Hoffman sign was considered positive if there was flexion of the patient's ipsilateral thumb or index finger (14). Patients were assessed for neurodynamic dysfunction and range of motion using the following maneuvers commonly used in physical therapy practice: seated slump testing, ankle dorsiflexion, passive straight leg raise, the upper limb neurodynamic test 1 (also known as the upper limb tension test with a median nerve bias), prone knee bend, and prone press-up. Methods for performing the examination maneuvers have been described in detail elsewhere $(10,11)$.

All patients were tested for orthostatic intolerance using a 10min passive standing test $(3,15)$. Blood pressure and heart rate were recorded at 1-min intervals while the patient was supine for $5 \mathrm{~min}$, and then again at 1-min intervals while the patient was standing upright and motionless for $10 \mathrm{~min}$ with the upper back resting against the wall and with the heels two to six inches away. At completion of standing, patients had repeat heart rate and blood pressure measurements for two further minutes in the supine position. Patients were asked when supine and at 1- to 2min intervals while upright to report changes in symptoms on a $0-10$ scale with 0 meaning absence of the symptom and 10 being the worst severity imaginable. The diagnosis of postural orthostatic tachycardia syndrome (POTS) for individuals 1219 years required at least a 40 beat per minute (bpm) increase in heart rate between the lowest supine value and the peak while standing; for those 20 and older, a $30 \mathrm{bpm}$ increase was required (16).

The Institutional Review Board of the Johns Hopkins Medical Institutes had waived informed consent for a retrospective study using data collected as part of routine care.

\section{CASE REPORT (PATIENT 1)}

A 19-year-old male resident of Florida with a past history of Gilbert syndrome and allergies developed a cough, sore throat, 
headache, and fatigue on June 17, 2020. These symptoms began 3 days after a household exposure to a visiting relative who shortly thereafter had a positive SARS-CoV-2 RNA nucleic acid quantification test. Despite sleeping 3-4h more than usual per night, this adolescent felt exhausted and flu-like, and his SARSCoV-2 RNA nucleic acid quantification test was positive on June 18. He experienced a loss of sense of smell which persisted for several months. Both parents became ill at the same time, with confirmation of COVID-19 via a nucleic acid quantification test in his father and subsequent positive COVID-19 antibody tests in both.

Prior to his COVID-19 diagnosis, this patient was a college student and track and cross-country athlete, running on average 60-70 miles per week. Two weeks after the onset of his symptoms, his attempts to resume running resulted in an increased cough, labored breathing, and lightheadedness. By July 1, there was some improvement in the fatigue, and he was able to run three miles, however the cough remained. Throughout the rest of July, he continued to experience a decreased tolerance for running and an increase in post exertional malaise, characterized by lightheadedness, an increase in fatigue, and coughing. He also developed chest pressure, intermittent chest pain, and a significant increase in his heart rate after basic tasks such as walking to another room or showering. During very light activity (a game of cornhole, similar to bean bag toss) 2 months after the onset, his heart rate was $160-170 \mathrm{bpm}$ for $20-30 \mathrm{~min}$, followed by 3 days of PEM. A cardiac evaluation in mid-July, including an electrocardiogram (ECG), chest x-ray, and echocardiogram, revealed no abnormalities. A cardiopulmonary exercise test at 4 months after onset of illness showed a normal exercise ECG, but below average peak VO2 of $84 \%$ of predicted. A cardiac MRI showed no abnormalities. The troponin level was $0.009 \mathrm{mg} / \mathrm{mL}$ 6 weeks after the onset of illness.

We evaluated him 2 months after the onset of the COVID-19 infection, at which time his symptoms included constant fatigue, unrefreshing sleep, PEM after mild increases in activity, bifrontal and bi-temporal headaches, chest pain, occasional cough, leg pain, insomnia, frequent awakening, and mild anxiety and depression. He also had a pre-COVID-19 history of mild asthma, allergic inflammation, and several food intolerances.

His physical examination showed a healthy-looking young man in no distress. He had a Beighton score of $3 / 9$ for $>10$ degrees of hyperextensibility of the right elbow and both knees. His neurologic examination showed $2+$ symmetrical deeptendon reflexes with a bilaterally positive Hoffman sign. He had limited symptom-free range of motion on a seated slump test, lacking 30 degrees of full leg extension of the right and 60 degrees of the left. Passive straight leg raise end-range was limited at 35 degrees bilaterally. Upper limb neurodynamic test 1 lacked 50 degrees of elbow extension on the left and 40 degrees on the right. To investigate the lightheadedness and fatigue, a 10 -min passive standing test showed a $70 \mathrm{bpm}$ difference between his lowest supine and peak standing heart rate, consistent with a diagnosis of postural orthostatic tachycardia syndrome (Figure 1, Table 2).

A month after onset, his complete blood count showed a WBC of 5.1, hemoglobin 16.1, and platelet count of 255. His comprehensive metabolic panel was normal with the exception of

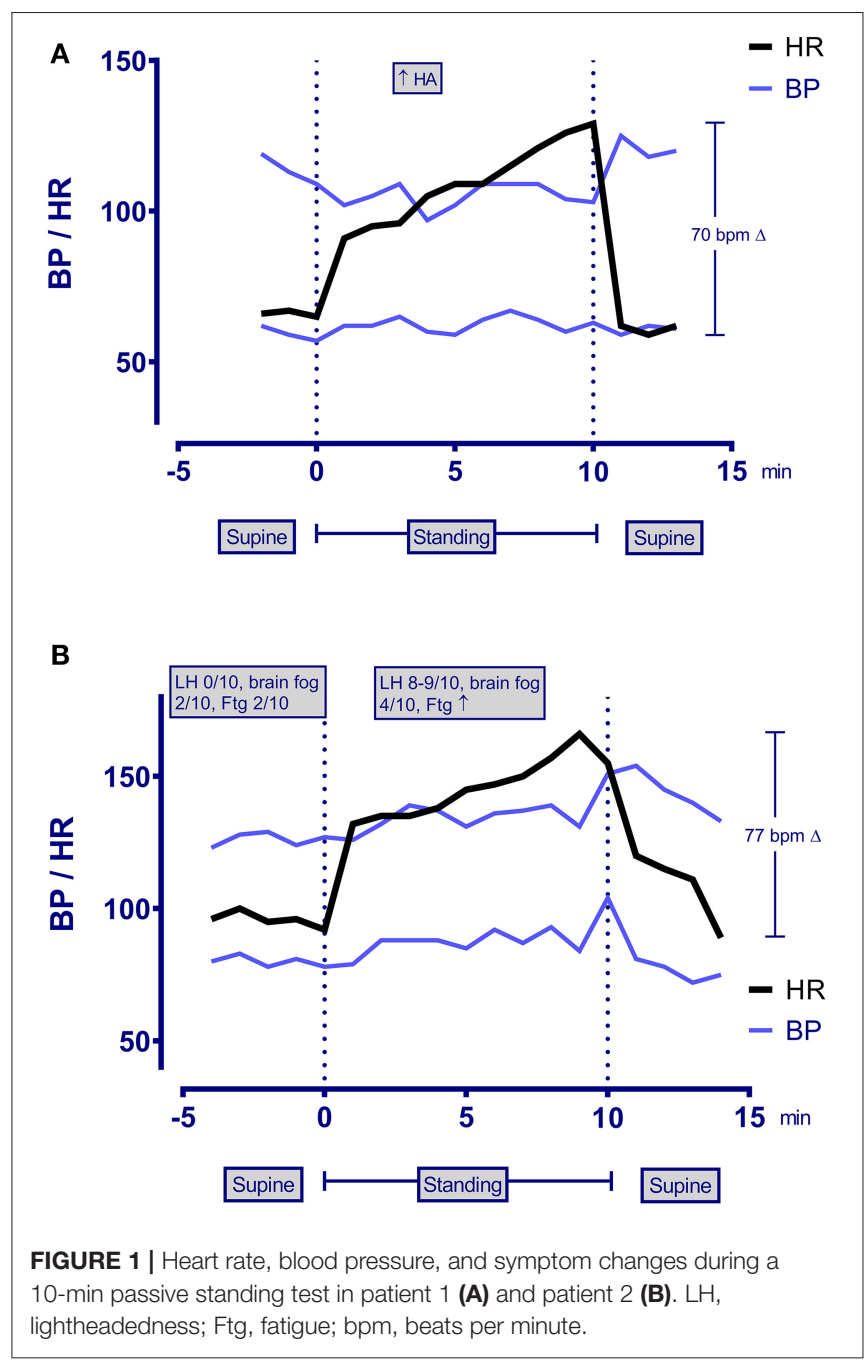

a total bilirubin of 1.5 (reference range, $0.2-1.1 \mathrm{mg} / \mathrm{dL}$ ) consistent with his prior diagnosis of Gilbert syndrome. His CK was normal at 79 (reference range, 44-196 U/L). The sedimentation rate was 6. In light of his allergic history, testing was also performed to evaluate the presence of mast cell activation disorder. Serum tryptase was normal at 5.4 (reference range, $<11.0 \mathrm{mcg} / \mathrm{L}$ ) but chromogranin A was mildly elevated at 144 (reference range, 25-140 $\mathrm{mg} / \mathrm{mL}$ ), and his plasma histamine was elevated to 4.2 (reference range, $\leq 1.8 \mathrm{mg} / \mathrm{mL}$ ); plasma histamine remained elevated on repeat testing 3 and 7 months after the onset of the illness.

After 6 months of illness, he satisfied the Institute of Medicine criteria for ME/CFS. Seven months post-COVID-19, his ability to function as he had pre-illness remains markedly decreased. His main symptoms consist of persistent fatigue, limited tolerance of exercise, unrefreshing sleep, PEM, lightheadedness, and headaches. He now tolerates two to three 15-min walks daily without provoking excessive tachycardia or PEM. Current treatments include Lexapro $5 \mathrm{mg}$ daily for post-illness anxiety, loratadine $10 \mathrm{mg}$ daily and famotidine $40 \mathrm{mg}$ twice daily for the 
allergic symptoms and elevations in histamine, methylphenidate $10 \mathrm{mg}$ each morning as a vasoconstrictor, along with compression garments and an increased sodium intake for POTS.

\section{RESULTS}

\section{Participants}

In addition to the patient reported above, two other individuals were referred to the clinic between August and October 2020. The demographic and clinical data on the three participants are displayed in Table 1. As discussed above, patient 1 had a confirmed COVID-19 infection. Patients 2 and 3 had close contact with an individual with confirmed COVID-19 infection and developed anosmia and dysgeusia lasting up to 5 months. Nucleic acid quantification testing for COVID-19 was performed relatively late, 1 month after onset of illness in patient 2 . Nucleic acid quantification testing for patient 3 was not performed due to lack of availability, but two further household members developed similar symptoms within days of exposure to her. Of interest, antibody testing later was negative for patients 2 and 3 .

\section{Criteria for ME/CFS}

As shown in Table 2, all three participants met criteria for ME/CFS 6 months after the onset of symptoms. ME/CFS symptoms had been present from day one of the illness. None of the participants had a prior medical history of ME/CFS. Symptoms of orthostatic intolerance were also present at an early point of the initial respiratory illness, from 1 day to 2 weeks.
All had profound POTS on testing several months after the onset, as shown in Table 2, with the increment between lowest supine and peak standing heart rate within the first 10 min wellexceeding the diagnostic criteria, together with reproduction of orthostatic symptoms.

\section{Other Clinical and Allergic Phenomena}

Allergic symptoms and history were present in all participants as displayed in Table 3. Notably, one patient had a history of oral allergy syndrome, another had urticaria after exposure to citrus, and the third had cutaneous features consistent with mast cell activation (dermatographism and facial flushing). Table 3 also displays the pertinent physical examination findings. Two of the three patients had an abnormal Hoffman sign. Patient 2 met criteria for hypermobile Ehlers Danlos syndrome. Neurodynamic testing measures commonly used in physical therapy to assess for changes in, among other things, neural gliding function in the trunk and limbs, revealed restricted range of motion findings in all three patients.

\section{DISCUSSION}

This case series describes one patient with confirmed SARS-CoV2 infection and two with highly probable SARS-CoV-2 infection in whom the diagnostic criteria for ME/CFS were satisfied by month 6 of the illness. Fatigue has previously been reported as a common acute symptom of COVID-19, with a prevalence reaching $80 \%$ in the first month and remaining as high as 53\% 2

\begin{tabular}{|c|c|c|c|c|c|c|c|c|c|}
\hline \multirow[t]{3}{*}{1} & 19 & $\mathrm{M}$ & 6/17/2020 & + & $6 / 18 / 20$ & $+\lg G$ & $1 / 19 / 21$ & $\begin{array}{l}\text { Exposed to relative } 3 \text { days } \\
\text { before onset. Other } \\
\text { household contacts also } \\
\text { developed COVID-19 } \\
\text { symptoms and had positive } \\
\text { PCR or antibody tests }\end{array}$ & $\begin{array}{l}\text { Cough, sore throat, } \\
\text { headache and fatigue at } \\
\text { onset without fever followed } \\
\text { by loss of sense of smell. }\end{array}$ \\
\hline & & & & + & $7 / 01 / 20$ & $+\operatorname{lgM}$ & $1 / 19 / 21$ & & \\
\hline & & & & - & $7 / 15 / 20$ & & & & \\
\hline 2 & 30 & $\mathrm{~F}$ & 3/19/2020 & - & $4 / 09 / 20$ & - & $4 / 09 / 20$ & $\begin{array}{l}\text { Exposed } 2 \text { days earlier to } \\
\text { co-worker in an office two } \\
\text { doors down the hall whose } \\
\text { COVID-19 PCR test was } \\
\text { positive }\end{array}$ & $\begin{array}{l}\text { Mild cough, fatigue, and } \\
\text { low-grade temperature } \\
\text { elevation at onset followed } \\
\text { by loss of taste and smell at } \\
\text { day } 5 \text { (persisting for } 5-6 \\
\text { weeks) }\end{array}$ \\
\hline 3 & 22 & $\mathrm{~F}$ & 4/07/2020 & Not performed & & - & $9 / 20 / 20$ & $\begin{array}{l}\text { Exposed to a positive case } \\
\text { and within days developed } \\
\text { symptoms. In the next } \\
\text { week, mother and boyfriend } \\
\text { developed fever, myalgias, } \\
\text { chills, headache, and } \\
\text { shortness of breath }\end{array}$ & $\begin{array}{l}\text { Low grade fever, sore throat, } \\
\text { fatigue, and shortness of } \\
\text { breath for } 2 \text { weeks. }\end{array}$ \\
\hline
\end{tabular}

PCR, polymerase chain reaction/nucleic acid quantification test. 


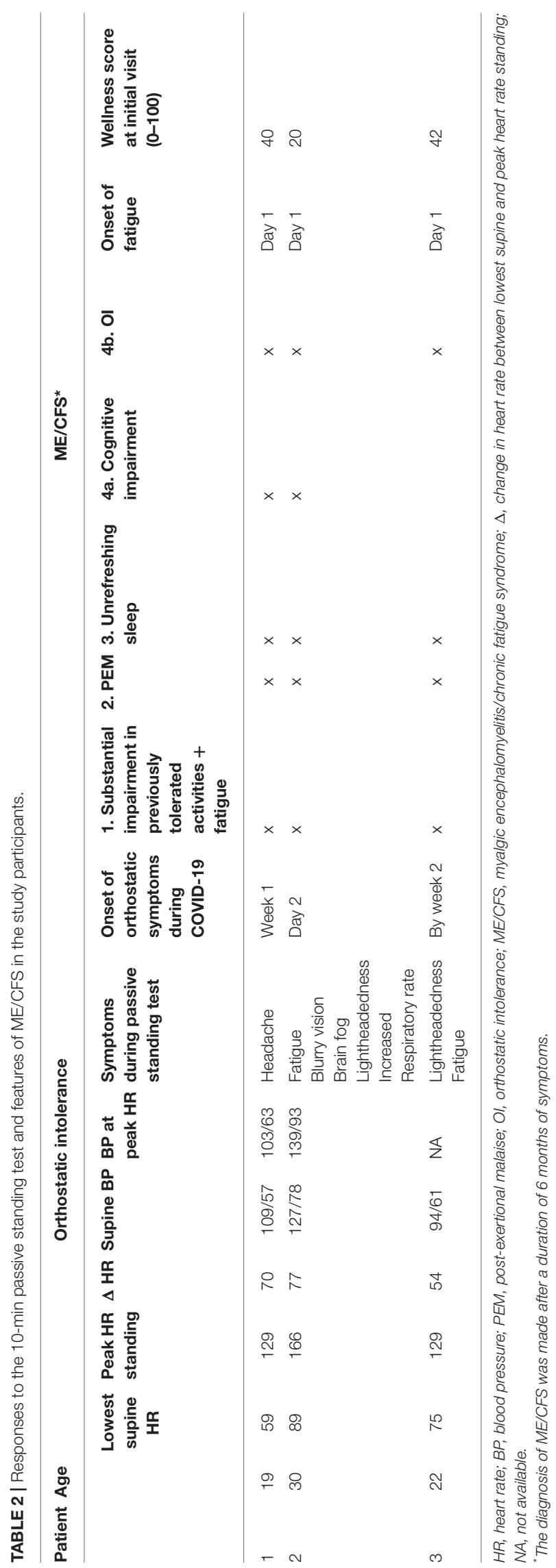

months after the onset (17). Our work parallels the findings of a recent survey of 3,762 international COVID-19 patients by Davis and colleagues (8). They reported fatigue, PEM, and cognitive dysfunction as the three most common symptoms persisting after 6 months. Of the total survey population, 2,308 respondents reported tachycardia. Of all the respondents, only $8.43 \%$ were hospitalized. The probability of having fatigue was high from day one and the probability of having PEM peaked and plateaued around week six.

Several observations from our case series warrant further emphasis. First, all three individuals had relatively mild respiratory symptoms and none required hospitalization. This is consistent with observations from other groups that persistent fatigue following COVID-19 infection is independent of the severity of the initial infection (18). The potential for marked impairment in function after relatively mild respiratory illnesses contrasts with the emergence of ME/CFS after other infectious illnesses. In the 10-13\% of individuals who meet criteria for ME/CFS 6 months following infectious mononucleosis, the risk of ME/CFS is related to the severity of the initial infection (19-21). The occurrence of $\mathrm{ME} / \mathrm{CFS}$ after relatively mild viral illnesses raises the question of how many ME/CFS cases before the COVID19 pandemic might have been due to mild, sub-clinical, or asymptomatic infections.

Second, as early as within the first 2 days and certainly within the first 2 weeks, all three developed symptoms of orthostatic intolerance and ultimately met criteria for POTS, which has been reported as a post-COVID-19 phenomenon by several groups $(8,22-25)$. Similar reports of dysautonomia followed the SARSCoV-1 pandemic (26). While the 10-min passive standing tests to confirm the diagnosis of POTS were conducted 5-7 months after the onset of COVID-19, the orthostatic symptoms were present at an early point, suggesting that autonomic symptoms could have been a direct result of the viral infection rather than a consequence of inactivity or deconditioning. In those diagnosed with POTS following COVID-19 infection, there has been a variable onset of orthostatic symptoms. Miglis (22) reported palpitations developing on day two of the COVID-19 illness in a 26 -year-old female nurse. She had noticed tachycardia by day seven of the illness. Kanjwal et al. reported a 36-year-old female who began to develop fatigue, dizziness, and palpitations with postural changes 3-4 weeks after the initial COVID-19 infection (25). Given the delay between the acute illness and the orthostatic symptoms, these authors speculated that autoimmunity was a likely mechanism for the onset of POTS, as has been reported by several groups (27-30). Novak (23) described a similar patient who developed orthostatic symptoms 1 month after the onset of acute COVID-19 infection, in whom intravenous immunoglobulin was partially successful. Further attention to the timing of the onset of orthostatic symptoms has the potential to help determine whether autonomic symptoms result from direct infection by the virus, sympathetic activation as part of the immune response, mast cell activation, or autoimmunity (31). In heterogeneous disorders like POTS, each of these mechanisms could be important for subsets of patients and might warrant different approaches to treatment. Based on these reports of 
TABLE 3 | Past medical history and physical examination abnormalities.

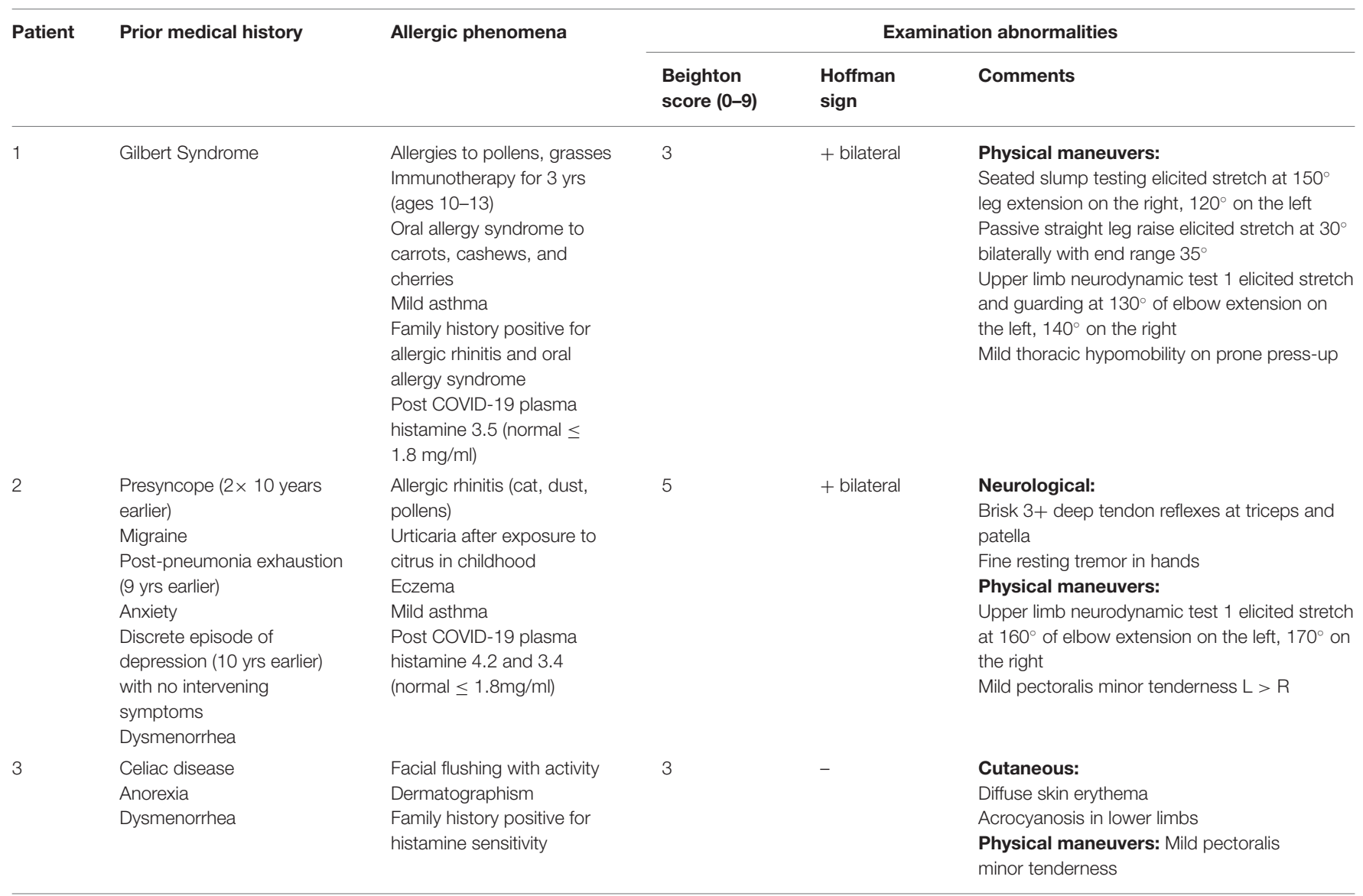

orthostatic intolerance in patients with chronic symptoms postCOVID-19, and the high prevalence of orthostatic intolerance in those with established ME/CFS, we would recommend at least $10 \mathrm{~min}$ of orthostatic testing for all patients reporting chronic fatigue in the context of long COVID.

Third, range of motion impairments have been found more commonly in individuals with ME/CFS than in healthy controls and are important in the pathogenesis of symptoms $(11,32)$. The application of a longitudinal neural strain such as that imposed by a straight leg raise maneuver is capable of aggravating fatigue and other symptoms for at least $24 \mathrm{~h}$ (33). The mechanism for these range of motion impairments is unknown, but possible explanations include the result of previous musculoskeletal injuries, excessive guarding around hypermobile joints, postinfectious inflammation, and reduced activity in response to an illness (34). While two of our three patients presented with range of motion impairments, their pre-COVID-19 range of motion measurements are unknown. Therefore, it is impossible to tell whether these impairments preceded the onset of ME/CFS or were a result of the viral illness.

Fourth, all patients in our series had prominent histories of allergic inflammation. Afrin and colleagues and others (35-37) have hypothesized that mast cell activation can play an important pathophysiologic role in the hyperinflammatory response to COVID-19. Two of the three patients have had sustained elevations in plasma histamine, and both have had improvement in fatigue and cognitive dysfunction in response to treatment with drugs that block the $\mathrm{H} 1$ histamine receptor, consistent with mast cell activation. Further work is needed to determine the prevalence of similar allergic histories and evidence of mast cell activation syndrome (38) in others with prolonged symptoms for ME/CFS after COVID-19. If allergic inflammation and mast cell activation are common, it would be important to determine whether medications with antihistamine properties or medications that are capable of stabilizing mast cell membranes will prove effective in ameliorating the symptoms of postCOVID-19 ME/CFS.

Fifth, neuroanatomic abnormalities have been recognized in a subset of those with ME/CFS symptoms, including Chiari malformation, congenital or acquired cervical stenosis, and instability at the skull base or in the spine. Heffez (39) has described 270 patients with fibromyalgia among whom $64 \%$ had hyper-reflexia and $26 \%$ had a positive Hoffman sign (39). Our research group has reported a series of three patients in whom congenital or acquired cervical stenosis was a treatable cause of refractory orthostatic intolerance and other ME/CFS symptoms (12). The presence of abnormal Hoffman signs in two of our post-COVID-19 patients was unexpected after an acute illness. Long term study will be needed to determine whether these abnormalities were transient and related to the viral 
infection or persistent and related to underlying neuroanatomic abnormalities that predisposed patients to prolonged symptoms and autonomic dysfunction.

\section{LIMITATIONS}

This report of three cases establishes the potential for adolescents and young adults who have mild respiratory illnesses from confirmed or probable COVID-19 to develop prolonged symptoms consistent with ME/CFS. While one patient had proven COVID-19 infection, we could not confirm the presence of COVID-19 in the other two, a problem that was complicated by the lack of availability of testing early in the pandemic. These two patients had highly probable COVID-19 based on their close temporal exposure to confirmed cases and based on characteristic symptoms such as anosmia and dysgeusia. A curious finding was that none of the two probable cases developed antibodies to COVID-19 in the convalescent phase of their illness. Whether impaired production of antibodies is a risk-factor for prolonged symptoms after COVID-19 or is related to a sampling anomaly will need to be assessed in larger samples. Because these patients were referred to a specialist clinic at a tertiary care center, we cannot know whether the clinical features we observed will prove to be common across the general population of those with prolonged symptoms after COVID-19.

\section{CONCLUSION}

Our evaluation of this sample of three patients suggests that $\mathrm{ME} / \mathrm{CFS}$ can be triggered by confirmed or probable COVID-19 in adolescents and young adults. Komaroff and Bateman (1) predict that over 10 million new cases of ME/CFS will be triggered by COVID-19 globally. Further work is needed to determine the pathogenesis of ME/CFS after COVID-19 and how to treat these patients optimally to promote their return to their pre-COVID19 quality of life. Our study identifies several comorbid features that could be treated including ROM limitations that could respond to manual forms of therapy, orthostatic intolerance and POTS for which there are multiple non-pharmacologic and pharmacologic therapies, treatable allergic phenomena, and neurologic abnormalities that may require specific treatment. If

\section{REFERENCES}

1. Komaroff AL, Bateman L. Will COVID-19 lead to myalgic encephalomyelitis/chronic fatigue syndrome? Front Med. (2021) 7:606824. doi: 10.3389/fmed.2020.606824

2. Nath A. Long-haul COVID. Neurology. (2020) 95:55960. doi: 10.1212/WNL.0000000000010640

3. Institute of Medicine. Beyond Myalgic Encephalomyelitis/Chronic Fatigue Syndrome: Redefining an Illness. Washington, DC: The National Academies Press (2015).

4. Low PA, Sandroni P, Joyner M, Shen WK. Postural tachycardia syndrome (POTS). J Cardiovasc Electrophysiol. (2009) 20:3528. doi: 10.1111/j.1540-8167.2008.01407.x

5. Roma M, Marden CL, Flaherty MAK, Jasion SE, Cranston EM, Rowe PC. Impaired health-related quality of life in adolescent myalgic non-pandemic ME/CFS provides any guidance, the treatments for each patient are likely to vary based on the contributions of comorbid conditions. Whether post-COVID-19 patients are more homogeneous remains to be determined, but the expected number of new cases provides an opportunity to study diagnostic procedures, including standing and head-up tilt testing, as well as candidate therapies in an organized manner. These efforts also have the potential to inform the treatment of individuals with non-pandemic ME/CFS.

\section{DATA AVAILABILITY STATEMENT}

The datasets presented in this article are not readily available because: the main data from this case series is included in this article. Requests to access the datasets should be directed to prowe@jhmi.edu.

\section{ETHICS STATEMENT}

The studies involving human participants were reviewed and approved by Johns Hopkins Institutional Review Board. Written informed consent for participation was not required for this study in accordance with the national legislation and the institutional requirements. Written informed consent was obtained from the individual(s) for the publication of any potentially identifiable images or data included in this article.

\section{AUTHOR CONTRIBUTIONS}

LP wrote the initial draft and was involved in critical review of the final manuscript. SS, RLV, NP, RS, and PR were instrumental to the clinical care of patients, and have contributed to the writing and review of the manuscript. RLV contributed to the writing and critical review of the manuscript. All authors contributed to the article and approved the submitted version.

\section{FUNDING}

PR was supported by the Sunshine Natural Wellbeing Foundation Professorship in Chronic Fatigue and Related Conditions. encephalomyelitis/chronic fatigue syndrome: the impact of core symptoms. Front Pediatr. (2019) 7:26. doi: 10.3389/fped.2019.00026

6. Stewart JM, Gewitz MH, Weldon A, Arlievsky N, Li K, Munoz J. Orthostatic intolerance in adolescent chronic fatigue syndrome. Pediatrics. (1999) 103:116-21. doi: 10.1542/peds. 103.1.116

7. van Campen CMC, Verheugt FWA, Rowe PC, Visser FC. Cerebral blood flow is reduced in ME/CFS during head-up tilt testing even in the absence of hypotension or tachycardia: a quantitative, controlled study using Doppler echography. Clin Neurophysiol Pract. (2020) 5:50-8. doi: 10.1016/j.cnp. 2020.01.003

8. Davis HE, Assaf GS, McCorkell L, Wei H, Low RJ, Re'em $\mathrm{Y}$, et al. Characterizing long COVID in an international cohort: 7 months of symptoms and their impact. bioRxiv. (2020). doi: 10.1101/2020.12.24.20248802 
9. Bou-Holaigah I, Rowe PC, Kan J, Calkins H. The relationship between neurally mediated hypotension and the chronic fatigue syndrome. JAMA. (1995) 274:961-7. doi: 10.1001/jama.1995.03530120053041

10. Roma M, Marden CL, De Wandele I, Francomano CA, Rowe PC. Postural tachycardia syndrome and other forms of orthostatic intolerance in Ehlers-Danlos syndrome. Auton Neurosci. (2018) 215:89-96. doi: 10.1016/j.autneu.2018.02.006

11. Rowe PC, Marden CL, Flaherty MAK, Jasion SE, Cranston EM, Johns AS, et al. Impaired range of motion of limbs and spine in chronic fatigue syndrome. $J$ Pediatr. (2014) 165:360-6. doi: 10.1016/j.jpeds.2014.04.051

12. Rowe PC, Marden CL, Heinlein S, Edwards CC. Improvement of severe myalgic encephalomyelitis/chronic fatigue syndrome symptoms following surgical treatment of cervical spinal stenosis. J Transl Med. (2018) 16:21. doi: 10.1186/s12967-018-1397-7

13. Rowe PC, Marden CL, Jasion SE, Cranston EM, Flaherty MA, Kelly KJ. Cow's milk protein intolerance in adolescents and young adults with chronic fatigue syndrome. Acta Paediatr. (2016) 105:e412-8. doi: 10.1111/apa.13476

14. Malanga GA, Landes P, Nadler SF. Provocative tests in cervical spine examination: historical basis and scientific analyses. Pain Physician. (2003) 6:199-205. doi: 10.36076/ppj.2003/6/199

15. Roma M, Marden CL, Rowe PC. Passive standing tests for the office diagnosis of postural tachycardia syndrome: new methodological considerations. Fatigue. (2018) 6:179-92. doi: 10.1080/21641846.2018.1512836

16. Freeman R, Wieling W, Axelrod FB, Benditt DG, Benarroch E, Biaggioni I, et al. Consensus statement on the definition of orthostatic hypotension, neurally mediated syncope and the postural tachycardia syndrome. Clin Auton Res. (2011) 21:69-72. doi: 10.1007/s10286-011-0119-5

17. Carfi A, Bernabei R, Landi F, for the Gemelli Against COVID-19 Post-Acute Care Study Group. Persistent symptoms in patients after acute COVID-19. JAMA. (2020) 324:603-5. doi: 10.1001/jama.2020.12603

18. Townsend L, Dyer AH, Jones K, Dunne J, Mooney A, Gaffney F, et al. Persistent fatigue following SARS-CoV-2 infection is common and independent of severity of initial infection. PLOS ONE. (2020) 15:e0240784. doi: 10.1371/journal.pone.0240784

19. Hickie I, Davenport T, Wakefield D, Vollmer-Conna U, Cameron B, Vernon SD, et al. Post-infective and chronic fatigue syndromes precipitated by viral and non-viral pathogens: prospective cohort study. BMJ. (2006) 333:575. doi: 10.1136/bmj.38933.585764.AE

20. Katz BZ, Shiraishi Y, Mears CJ, Binns HJ, Taylor R. Chronic fatigue syndrome after infectious mononucleosis in adolescents. Pediatrics. (2009) 124:18993. doi: 10.1542/peds.2008-1879

21. Pedersen M, Asprusten TT, Godang K, Leegaard TM, Osnes LT, Skovlund E, et al. Predictors of chronic fatigue in adolescents six months after acute Epstein-Barr virus infection: a prospective cohort study. Brain Behav Immun. (2019) 75:94-100. doi: 10.1016/j.bbi.2018.09.023

22. Miglis MG, Prieto T, Shaik R, Muppidi S, Sinn D-I, Jaradeh S. A case report of postural tachycardia syndrome after COVID-19. Clin Auton Res. (2020) 30:449-51. doi: 10.1007/s10286-020-00727-9

23. Novak P. Post COVID-19 syndrome associated with orthostatic cerebral hypoperfusion syndrome, small fiber neuropathy and benefit of immunotherapy: a case report. eNeurologicalSci. (2020) 21:100276. doi: 10.1016/j.ensci.2020.100276

24. Dani M, Dirksen A, Taraborrelli P, Torocastro M, Panagopoulos $\mathrm{D}$, Sutton R, et al. Autonomic dysfunction in 'long COVID': rationale, physiology and management strategies. Clin Med. (2021) 21:e63-7. doi: 10.7861/clinmed.2020-0896

25. Kanjwal K, Jamal S, Kichloo A, Grubb BP. New-onset postural orthostatic tachycardia syndrome following coronavirus disease 2019 infection. J Innov Card Rhythm Manag. (2020) 11:4302-4. doi: 10.19102/icrm.2020. 111102
26. Lo YL, Leong HN, Hsu LY, Tan TT, Kurup A, Fook-Chong S, et al. Autonomic dysfunction in recovered severe acute respiratory syndrome patients. Can J Neurol Sci. (2005) 32:264. doi: 10.1017/S0317167100004108

27. Li H, Yu X, Liles C, Khan M, Vanderlinde-Wood M, Galloway A, et al. Autoimmune basis for postural tachycardia syndrome. J Am Heart Assoc. (2014) 3:e000755. doi: 10.1161/JAHA.113.000755

28. Gunning WT, 3rd, Kvale H, Kramer PM, Karabin BL, Grubb BP. Postural orthostatic tachycardia syndrome is associated with elevated G-protein coupled receptor autoantibodies. J Am Heart Assoc. (2019) 8:e013602. doi: 10.1161/JAHA.119.013602

29. Fedorowski A, Li H, Yu X, Koelsch KA, Harris VM, Liles C, et al. Antiadrenergic autoimmunity in postural tachycardia syndrome. Europace. (2017) 19:1211-9. doi: 10.1093/europace/euw154

30. Loebel M, Grabowski P, Heidecke H, Bauer S, Hanitsch LG, Wittke K, et al. Antibodies to $\beta$ adrenergic and muscarinic cholinergic receptors in patients with Chronic Fatigue Syndrome. Brain Behav Immun. (2016) 52:329. doi: 10.1016/j.bbi.2015.09.013

31. Goldstein DS. The extended autonomic system, dyshomeostasis, and COVID19. Clin Auton Res. (2020) 30:299-315. doi: 10.1007/s10286-020-00714-0

32. Rowe PC, Marden CL, Flaherty MAK, Jasion SE, Cranston EM, Fontaine KR, et al. Two-year follow-up of impaired range of motion in chronic fatigue syndrome. J Pediatr. (2018) 200:249-53.e1. doi: 10.1016/j.jpeds.2018.05.012

33. Rowe PC, Fontaine KR, Lauver M, Jasion SE, Marden CL, Moni $\mathrm{M}$, et al. Neuromuscular strain increases symptom intensity in chronic fatigue syndrome. PLoS ONE. (2016) 11:e0159386. doi: 10.1371/journal.pone.0159386

34. Rowe P, Fontaine K, Violand R. Neuromuscular strain as a contributor to cognitive and other symptoms in chronic fatigue syndrome: hypothesis and conceptual model. Front Physiol. (2013) 4:115. doi: 10.3389/fphys.2013.00115

35. Afrin LB, Weinstock LB, Molderings GJ. Covid-19 hyperinflammation and post-Covid-19 illness may be rooted in mast cell activation syndrome. Int J Infect Dis. (2020) 100:327-32. doi: 10.1016/j.ijid.2020.09.016

36. Malone RW, Tisdall P, Fremont-Smith P, Liu Y, Huang X-P, White KM, et al. COVID-19: Famotidine, histamine, mast cells, and mechanisms. Research Square. (2021). doi: 10.21203/rs.3.rs-30934/v3

37. Kempuraj D, Selvakumar GP, Ahmed ME, Raikwar SP, Thangavel R, Khan A, et al. COVID-19, mast cells, cytokine storm, psychological stress, and neuroinflammation. Neuroscientist. (2020) 26:402-14. doi: 10.1177/1073858420941476

38. Afrin LB, Ackerley MB, Bluestein LS, Brewer JH, Brook JB, Buchanan AD, et al. Diagnosis of mast cell activation syndrome: a global "consensus-2". Diagnosis. (2020). doi: 10.1515/dx-2020-0005

39. Heffez DS, Ross RE, Shade-Zeldow Y, Kostas K, Shah S, Gottschalk R, et al. Clinical evidence for cervical myelopathy due to Chiari malformation and spinal stenosis in a non-randomized group of patients with the diagnosis of fibromyalgia. Eur Spine J. (2004) 13:516-23. doi: 10.1007/s00586-004-0672-x

Conflict of Interest: RLV was employed by company Rick Violand, PT, LLC.

The remaining authors declare that the research was conducted in the absence of any commercial or financial relationships that could be construed as a potential conflict of interest.

Copyright (c) 2021 Petracek, Suskauer, Vickers, Patel, Violand, Swope and Rowe. This is an open-access article distributed under the terms of the Creative Commons Attribution License (CC BY). The use, distribution or reproduction in other forums is permitted, provided the original author(s) and the copyright owner(s) are credited and that the original publication in this journal is cited, in accordance with accepted academic practice. No use, distribution or reproduction is permitted which does not comply with these terms. 